\title{
A DOCÊNCIA VIRTUAL E SABERES DOCENTES: UM ESTUDO DA TUTORIA NA REDE E-TEC BRASIL'
}

\author{
Luciane Penteado Chaquime* \\ Daniel Mill**
}

\begin{abstract}
RESUMO
$\mathrm{Na}$ atuação como mediador do processo de ensino-aprendizagem em cursos de Educação a Distância por meio de tecnologias digitais de informação e comunicação, o tutor virtual mobiliza, por um lado, saberes que compõem a base de conhecimento necessária à docência em geral. Por outro, constrói novos saberes ao refletir sobre sua prática, ampliando e diversificando essa base. Partindo desse contexto, o artigo apresenta resultados de uma pesquisa que buscou mapear os saberes do tutor virtual, identificando sua natureza. Para a realização da investigação, empregouse a triangulação metodológica e percorreu-se as seguintes etapas: levantamento e estudo de bibliografia; coleta de dados utilizando-se questionário com questões abertas e fechadas, entrevista individual, sessões de entrevistas coletivas e análise de documentação oficial; sistematização e análise dos dados. Os resultados observados demonstram que a experiência na tutoria virtual tem potencial formador ao possibilitar a construção de novos saberes e, com isso, ampliar a base de conhecimento necessária à docência.
\end{abstract}

Palavras-chave: Docência virtual. Saberes docentes. Formação de professores. Educação a Distância. Rede e-Tec Brasil.

\section{ABSTRACT}

\section{VIRTUAL TEACHING AND EDUCATIONAL KNOWLEDGE: A STUDY OF TUTORIALS USED IN BRAZIL'S E-TEC NETWORK}

Acting as a mediator in the teaching-learning process of Distance Education courses provided via digital information and communication technologies, the virtual tutor mobilizes knowledge that comprises the necessary base for teaching in general. At the same time, however, while reflecting upon his/her teaching, the tutor constructs new knowledge, which expands and diversifies his/her educational foundations. From this context, this article presents the results of a study that sought to map the virtual

\footnotetext{
1 Este artigo é resultante de pesquisa realizada no âmbito do Grupo Horizonte (Grupo de Estudos e Pesquisas sobre Inovação em Educação, Tecnologias e Linguagens) e do Programa de Pós-Graduação em Educação da UFSCar, com apoio financeiro do CNPq.

* Mestre em Educação pela Universidade Federal de São Carlos (UFSCar). Técnica em Assuntos Educacionais do Instituto Federal de Educação, Ciência e Tecnologia de São Paulo (IFSP) - Campus Matão. Endereço Institucional: Rua Stéfano D’Avassi, 625, Nova Cidade - Matão/SP. CEP: 15991-502. luciane.penteado@gmail.com

** Doutor em Educação pela Universidade Federal de Minas Gerais (UFMG). Professor Associado do Departamento de Educação (DEd) da Universidade Federal de São Carlos (UFSCar). Endereço Institucional: DEd-UFSCar - Rodovia Washington Luís (SP-310), km 235, São Carlos-SP. CEP: 13565-905. mill@ufscar.br
} 
tutor's knowledge and identify its nature. To carry out the research, methodological triangulation was employed and the following steps were taken: bibliographical compilation and study; data collection through a questionnaire with open and closed questions, individual interviews, group interview sessions and analysis of official documents; and systematization and analysis of data. The obtained results demonstrate that the experience in virtual tutoring has potential as a training method that enables the creation of new knowledge and thereby expands the knowledge base required for teaching.

Keywords: Virtual teaching. Teaching knowledge. Teacher training. Distance Education. e-Tec Brazil Network.

\section{RESUMEN}

\section{LA DOCENCIA VIRTUAL Y SABERES DOCENTES: UN ESTUDIO DE LA TUTORÍA EN LA RED E-TEC BRASIL}

En la actuación como mediador del proceso de enseñanza-aprendizaje en cursos de Educación a Distancia por medio de tecnologías digitales de información y comunicación, el tutor virtual moviliza, por un lado, saberes que componen la base de conocimiento necesaria a la docencia en general. Por otro, construye nuevos saberes al reflexionar sobre su práctica, ampliando y diversificando esa base. Partiendo de ese contexto, el artículo presenta resultados de una investigación que busco mapear los saberes del tutor virtual, identificando su naturaleza. Para la realización de la investigación, se empleó la triangulación metodológica y se recorrió las siguientes etapas: levantamiento y estudio de bibliografía; recolecta de datos utilizando cuestionarios con preguntas abiertas y cerradas, entrevista individual, sesiones de entrevistas colectivas y análisis de documentación oficial; sistematización y análisis de los datos. Los resultados observados demuestran que la experiencia en la tutoría virtual tiene potencial formador al posibilitar la construcción de nuevos saberes y, con eso, ampliar la base de conocimiento necesaria para la docencia.

Palabras clave: Docencia virtual. Saberes docentes. Formación de Profesores. Educación a Distancia. Red E-TEC Brasil.

\section{Introdução}

A contemporaneidade tem como uma de suas principais características a presença massiva das tecnologias digitais de informação e comunicação (TDIC). Inseridas na mediação social, essas tecnologias possibilitam mudanças na forma como os indivíduos se relacionam nas esferas da produção, do mercado, das relações culturais, afetivas e educacionais.

No que diz respeito à educação, a expansão das TDIC permitiu o avanço da modalidade a distância, favorecendo a proliferação de cursos dos mais variados tipos, como cursos de curta duração, de aperfeiçoamento, técnicos, de gra- duação e pós-graduação. Além disso, possibilitou propostas de Educação a Distância $(\mathrm{EaD})$ que rompem com os modelos mais arcaicos (baseados na autoinstrução e na verificação de resultados) em favor da construção de conhecimento por meio das interações entre alunos-alunos e alunos-professores nos ambientes virtuais de aprendizagem (AVA).

Para que a EaD mediada pelas TDIC seja implementada, é necessário um conjunto de profissionais que, atuando de forma coletiva, distribuída e colaborativa, desempenham o papel típico do professor da educação tradicional. Desse modo, tarefas como conhecer os alunos, planejar a aula e os conteúdos que serão trabalhados, escolher os 
recursos didáticos, elaborar atividades e avaliações, aplicá-las, corrigi-las e acompanhar o processo de ensino-aprendizagem de cada aluno e manejo da turma são distribuídas a vários profissionais que, em conjunto, formam o que Mill (2014) denominou "polidocência".

Dentre os profissionais da polidocência, o tutor virtual é figura central. Isso porque, ao atuar bem próximo ao aluno, interagindo diretamente no AVA como motivador do processo de ensino-aprendizagem, o tutor virtual representa a instituição, além de ser identificado, pelos alunos, como seu "professor" efetivamente.

No desempenho de seu papel de motivador/ orientador do processo de ensino-aprendizagem em cursos EaD mediados pelas TDIC, o tutor virtual atua como docente e, portanto, mobiliza alguns saberes típicos do educador. Parte desses saberes é, geralmente, construída durante sua formação inicial, em cursos de graduação. Outra porção, porém, é formada num processo contínuo ao longo da vida (REALI; TANCREDI; MIZUKAMI, 2008), em cursos realizados durante a carreira e, também, pelo exercício profissional. Por isso, para Tardif (2012, p. 36), o saber docente constitui-se "como um saber plural, formado pelo amálgama, mais ou menos coerente, de saberes oriundos da formação profissional e de saberes disciplinares, curriculares e experienciais". Por se tratar de saberes que são específicos e essenciais à profissão docente, Shulman $(1986,2005)$ denomina-os de "base de conhecimento para a docência".

Este artigo embasa-se nos resultados de uma investigação que buscou responder a seguinte questão: quais as principais transformações que podem ser observadas na docência ao longo dos anos de prática pedagógica na EaD? Sendo assim, um dos enfoques da investigação, ora apresentado, foi mapear os saberes do tutor virtual, identificando sua natureza. Dessa maneira, caracteriza-se como um estudo descritivo. As referências teóricas são os estudos de Shulman $(1986,2005)$ sobre a base de conhecimento necessária à profissão docente $\mathrm{e}$, ainda, os de Tardif $(2010,2012)$ acerca dos saberes docentes, especialmente os saberes experienciais, compreendidos como os que são construídos a partir da reflexão sobre a vivência das situações no contexto de trabalho e nas interações com os alunos. A partir desses referenciais, compreende-se que os saberes que constituem a base de conhecimento da docência, tanto presencial quanto virtual, são plurais e podem ser constituídos na formação inicial ou ao longo da carreira. A análise da base de conhecimento dos tutores virtuais da Rede e-Tec Brasil/IFSP toma como base a categorização de Mizukami (2004).

Os tutores virtuais que atuam nos cursos técnicos de Administração, Informática para a Internet e Profuncionário, oferecidos pelo Instituto Federal de Educação, Ciência e Tecnologia de São Paulo (IFSP), por meio da Rede e-Tec Brasil, foram os sujeitos da investigação, que valeu-se da triangulação metodológica (DUARTE, 2009) e perpassou as seguintes etapas: 1) levantamento e estudo de bibliografia visando o aprofundamento teórico e a definição de categorias de análise para subsidiar a elaboração dos instrumentos de coleta de dados e as análises; 2) coleta de dados realizada por meio dos seguintes instrumentos: questionário on-line elaborado com a ferramenta Limesurvey, contendo cinco grupos de questões abertas e fechadas, além do Termo de Consentimento Livre e Esclarecido (TCLE), enviado a 183 tutores virtuais e completado por 83 (45,3\% do total); entrevistas individuais com cinco tutores, a partir de um roteiro semiestruturado, das quais uma foi realizada virtualmente por chamada de voz com o uso do Skype; entrevistas coletivas ou sessões de diálogo em bate-papo, realizados em dois momentos (no primeiro, via mensagens do Facebook, participaram quatro tutores virtuais e, no segundo, via mensagens do Skype, participaram seis); e análise de documentação oficial relativa à $\mathrm{EaD}$ e à Rede e-Tec Brasil; e 4) sistematização e análise dos dados.

As próximas seções deste texto organizam-se da seguinte maneira: na seção dois, busca-se identificar os saberes dos tutores virtuais relacionados à base de conhecimento necessária à docência em geral. Na terceira seção, enfatiza-se a formação de saberes por meio da prática profissional da docência. A quarta seção enfoca a atuação do tutor virtual como mediador pedagógico em AVA e os saberes que constrói nessa experiência. Por fim, a quinta seção traz algumas considerações acerca dos resultados observados na investigação realizada. 


\section{0 tutor virtual e a base de conhecimento necessária à docência}

Partindo da categorização de Mizukami (2004) para os saberes descritos por Shulman (1986, 2005) como integrantes da base de conhecimento necessária à docência, tem-se: conhecimento do conteúdo específico, conhecimento pedagógico geral e conhecimento pedagógico do conteúdo. A seguir, apresenta-se uma aproximação dessa discussão com a docência virtual, marcadamente a tutoria a distância.

\subsection{O tutor virtual e o conhecimento do con-} teúdo específico

Segundo Shulman (1986, 2005), o conhecimento do conteúdo específico relaciona-se à quantidade e organização do conhecimento em si (específico sobre a matéria) na mente do professor. Pensar so- bre esse conhecimento vai além de saber a respeito de fatos ou conceitos. Requer compreensão sobre os processos, os procedimentos e as estruturas do conteúdo específico, ou seja, sobre como ele é construído dentro de cada área. Assim, professores bem preparados serão capazes de reconhecer quais conhecimentos são mais importantes para determinado contexto para enfatizá-los. Da mesma forma, saberão quais conhecimentos podem ser deixados de lado em determinada circunstância.

Além disso, compreende-se como conhecimento do conteúdo específico os saberes disciplinares de Tardif (2012), ou seja, aqueles constituídos por cada disciplina, disponíveis à sociedade e transmitidos nos cursos de graduação. Desta forma, organizamos, na Tabela 1, o conhecimento do conteúdo específico dos tutores virtuais investigados a partir das áreas de conhecimento da Capes $^{2}$ (COORDENAÇÃO DE APERFEIÇOAMENTO DE PESSOAL DE NÍVEL SUPERIOR, 2014).

Tabela 1 - Distribuição dos tutores virtuais por área de conhecimento e cursos em que atuam na Rede e-Tec Brasil/IFSP (em números absolutos e porcentagem)

\begin{tabular}{lllll}
\hline $\begin{array}{l}\text { Áreas de } \\
\text { conhecimento }\end{array}$ & $\begin{array}{l}\text { Formação geral } \\
\text { dos tutores } \\
\text { por área de } \\
\text { conhecimento }\end{array}$ & $\begin{array}{l}\text { Formação dos } \\
\text { tutores que atuam } \\
\text { no curso Técnico } \\
\text { em Administração }\end{array}$ & $\begin{array}{l}\text { Formação dos } \\
\text { tutores que atuam } \\
\text { no curso Técnico } \\
\text { em Informática } \\
\text { para a Internet }\end{array}$ & $\begin{array}{l}\text { Formação } \\
\text { dos tutores } \\
\text { que atuam no } \\
\text { Profuncionário }\end{array}$ \\
\hline $\begin{array}{l}\text { Ciências Exatas e } \\
\text { da Terra }\end{array}$ & $31(37,34 \%)$ & $7(22,58 \%)$ & $14(45,15 \%)$ & $10(32,23 \%)$ \\
Ciências Biológicas & $1(1,2 \%)$ & $0(0 \%)$ & $0(0 \%)$ & $1(100 \%)$ \\
$\begin{array}{l}\text { Engenharias } \\
\text { Ciências da Saúde }\end{array}$ & $11(13,25 \%)$ & $6(54,54 \%)$ & $4(36,36 \%)$ & $1(9,09 \%)$ \\
$\begin{array}{l}\text { Ciências Sociais } \\
\text { Aplicadas }\end{array}$ & $16(19,27 \%)$ & $12(75 \%)$ & $0(0 \%)$ & $3(75 \%)$ \\
Ciências Humanas & $12(14,45 \%)$ & $3(25 \%)$ & $0(0 \%)$ & $4(25 \%)$ \\
$\begin{array}{l}\text { Linguística, Letras } \\
\text { e Artes }\end{array}$ & $6(7,22 \%)$ & $1(16,66 \%)$ & $0(0 \%)$ & $5(83,33 \%)$ \\
Multidisciplinar & $2(2,4 \%)$ & $1(50 \%)$ & $0(0 \%)$ & $1(50 \%)$ \\
\hline Total & $83(100 \%)$ & $30(36 \%)$ & $19(23 \%)$ & $34(41 \%)$ \\
\hline
\end{tabular}

Fonte: Elaborada pelos autores deste artigo.

2 As Ciências Agrárias não constam na Tabela 1 porque nenhum dos tutores apontou formação relacionada a elas. 
O maior percentual de conhecimento do conteúdo específico apresentado na área de Ciências Exatas e da Terra $(37,34 \%)$ relaciona-se às áreas de conhecimento às quais pertencem os cursos oferecidos pela Rede e-Tec Brasil/IFSP e, ainda, aos requisitos exigidos pelos editais de seleção, especialmente os dos anos de 2010 e 2011, os quais detalham a necessidade de formação específica na área da disciplina em que o tutor virtual irá atuar.

Os tutores investigados foram consultados sobre a importância do conhecimento do conteúdo específico da disciplina para a atuação como mediador do processo de ensino-aprendizagem em AVA. A maioria deles (82\%) avaliou esse conhecimento como de grande importância para a prática da tutoria (Figura 1).

Figura 1 - Avaliação dos tutores virtuais sobre a importância dos saberes disciplinares para sua atuação (escala de 1 a 5 , sendo 1 = pouco importante e $5=$ muito importante)

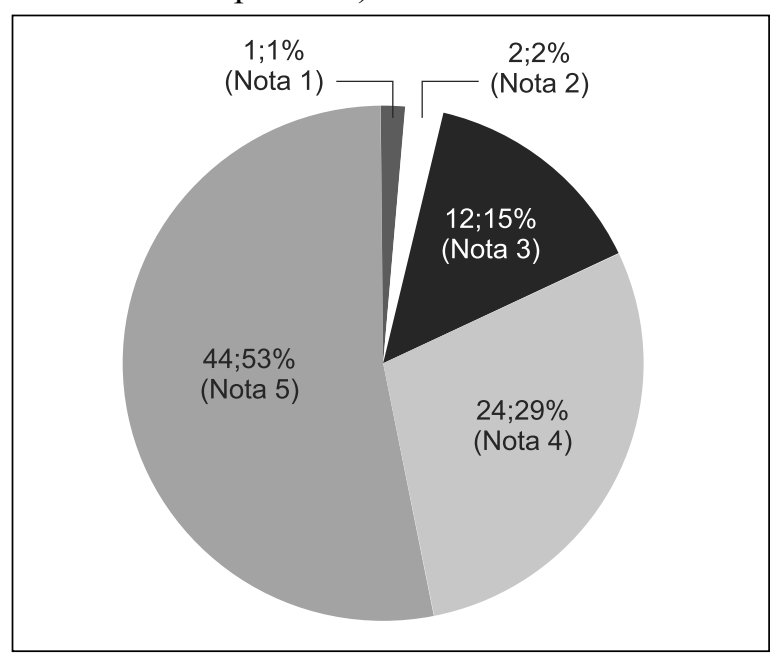

Fonte: Elaborada pelos autores deste artigo.

Como forma de ilustrar a avaliação apresentada na Figura 1, um dos sujeitos da pesquisa ressalta o valor do domínio de conteúdo da disciplina em que atua. ${ }^{3}$

$3 \mathrm{Na}$ consulta feita aos tutores por questionário e entrevista, havia questões abertas, para comentários livres ou subjetivos. Nesse texto, alguns extratos das falas permearão a análise. Sendo o tutor virtual um dos principais membros da polidocência, ele atua como docente nas interações que estabelece com os alunos de cursos EaD mediados pelas TDIC. Nos extratos/comentários, os tutores foram identificados como docentes virtuais e cada um recebeu uma letra do alfabeto para diferenciação, mas preservando-se o sigilo quanto ao nome do sujeito investigado.
Eles [tutores virtuais] são colocados muitas vezes sem dominar a matéria em que estão, porque supostamente o papel deles é só tirar dúvida do aluno. Aí, se ele tiver dúvida, ele pergunta pro formador, então, coloca-se esse tutor como um mero intermediário, que [...], na minha visão, ele não é. Ele teria que ter o domínio, a mesma coisa que eu 'tiver' tirando dúvida de um aluno em sala de aula, se eu não dominar a matéria, como que eu vou esclarecer essa dúvida? (Comentário 1 - Docente Virtual A).

A fala desse tutor deixa clara a importância do conhecimento do conteúdo específico para o desempenho satisfatório do papel de mediador do processo de ensino-aprendizagem em cursos EaD mediados pelas TDIC.

\section{2. $O$ tutor virtual e o conhecimento peda- gógico geral}

Compõem essa categoria os conhecimentos relacionados a teorias e princípios do processo de ensino-aprendizagem; conhecimentos relativos às características dos alunos, de como eles aprendem e da forma como se estabelecem as interações em sala de aula; conhecimentos referentes aos contextos educacionais; conhecimentos sobre outras disciplinas e que podem ser trabalhados interdisciplinarmente; conhecimentos acerca do currículo e da política educacional; e conhecimentos das finalidades, metas e dos fundamentos históricos e filosóficos da educação (MIZUKAMI, 2004).

É possível incluir na categoria do conhecimento pedagógico geral os saberes da formação profissional ou saberes profissionais, os quais consistem no "conjunto de saberes transmitidos pelas instituições de formação de professores" (TARDIF, 2012, p. 36). Para esse autor, enquadram-se nos saberes profissionais, ainda, os saberes pedagógicos "provenientes de reflexões sobre a prática educativa no sentido amplo do termo, reflexões racionais e normativas que conduzem a sistemas mais ou menos coerentes de representação e de orientação da atividade educativa" (TARDIF, 2012, p. 37). Os saberes profissionais e pedagógicos podem ser constituídos durante a formação em cursos de licenciatura, uma vez que compõem o currículo desses cursos.

Na investigação, constatou-se que 34 (40,96\%) dos 83 pesquisados ingressaram na docência em 
geral apenas com saberes disciplinares, pois graduaram-se em cursos de bacharelado e tecnologia, apenas. Por outro lado, observou-se que 57,83\% (48 em números absolutos) do total de tutores virtuais pesquisados apontaram formação em licenciaturas, como primeira ou segunda graduação. Tal dado pode ser considerado um indicativo de que boa parte deles já ingressou na tutoria virtual com saberes pedagógicos constituídos. Nesse sentido, compreende-se que a prática pedagógica na $\mathrm{EaD}$ tem potencial para ampliar os saberes pedagógicos, especialmente para os docentes sem formação em licenciaturas, conforme ilustra o Comentário 2, a seguir, referente aos saberes construídos na atuação como tutor virtual.

Fortalecimento de conteúdos diversos sobre o conhecimento da rotina escolar juntamente com conceitos de gestão e utilização dos instrumentos jurídicos que normatizam e dão suporte à gestão. (Comentário 2 - Docente Virtual B).

Além disso, observou-se que os tutores virtuais valorizam saberes referentes ao conhecimento pedagógico em geral para sua atuação como mediadores do processo de ensino-aprendizagem no AVA, especialmente a importância de se conhecer os alunos e suas dificuldades. As falas abaixo demonstram essa valorização.

$\mathrm{Eu}$ acho que ser docente no virtual tem umas características muito marcantes. Você parece que compartilha algumas questões mais pessoais com o aluno para deixá-lo mais confortável, para deixar que se aproxime mais de você, para ele ter confiança no seu trabalho, expor para ele o quanto você pode colaborar com a aprendizagem dele, e, também, uma coisa que, infelizmente, muitas vezes no presencial a gente abafa um pouco é utilizar o conhecimento prévio do aluno. No virtual, a gente parece que enfatiza muito mais e deixa muito mais o conhecimento prévio do aluno ser mostrado do que no presencial. Isso foi uma coisa assim que eu notei demasiadamente. (Comentário 3 - Docente Virtual C).

Pensando na relação professor/aluno, acredito que entendemos um pouco melhor das ansiedades dos alunos [na EaD]. (Comentário 4-Docente Virtual D).

Os Comentários 3 e 4 relacionam-se às interações estabelecidas entre os tutores e os alunos no AVA e esclarecem que a mediação pedagógica na modalidade $\mathrm{EaD}$ favorece o contato mais próximo com o estudante, permitindo, assim, ficar a par de seus anseios, de suas dificuldades e de seus conhecimentos prévios sobre a disciplina para melhor auxiliá-los durante o processo de ensino-aprendizagem. Dessa maneira, percebe-se, nas falas em destaque, que a experiência na tutoria virtual pode contribuir para a formação de saberes referentes ao conhecimento pedagógico geral. Isso porque, na medida em que tutores e alunos interagem de forma mais estreita, é possível ao tutor aproximar-se da realidade do aluno e conhecê-lo melhor para atuar contextualizando o processo de ensino-aprendizagem.

\subsection{O tutor virtual e o conhecimento peda- gógico do conteúdo}

O conhecimento pedagógico do conteúdo é definido por Shulman (1986) como o conhecimento específico para ensinar. Dele fazem parte as ideias, as analogias, as ilustrações, os exemplos, as demonstrações, entre outras representações que podem ser elaboradas para tornar os conhecimentos de determinada área acessíveis aos alunos. Em resumo, refere-se à maneira de formular o conhecimento específico para que seja compreensível a outras pessoas.

Esse conhecimento envolve a compreensão de como tornar uma aprendizagem mais fácil ou mais difícil e é derivado de pesquisas e também da sabedoria que vem da prática (SHULMAN, 1986). Assim, é preciso que o professor tenha ciência dos conhecimentos prévios dos alunos sobre o tema que estudarão para que, a partir disso, possa elaborar estratégias que permitam a reorganização e a compreensão dos discentes acerca daquele determinado assunto de estudo.

$\mathrm{Na}$ pesquisa, constatou-se que os tutores virtuais valorizam as interações estabelecidas com os discentes no AVA, pois, por meio delas, conhecem o perfil, as dificuldades e as vivências anteriores dos estudantes. Além disso, e conforme explicitado na subseção anterior, atribuem importância a esse saber, uma vez que, a partir dele, podem escolher melhores estratégias para mediar o processo educativo, tornando a aprendizagem mais fácil ou mais difícil. 
Com o objetivo de avaliar se, na visão dos tutores pesquisados, o aprendizado é mais difícil ou mais fácil quando é mediado pelas TDIC, questionou-se sobre o processo de ensino-aprendizagem nas modalidades presencial e EaD. Como resultado, $60,24 \%$ dos tutores virtuais avaliaram que o aluno aprende igualmente em ambas as modalidades; $24,09 \%$ afirmaram que na educação presencial o aluno aprende melhor do que na $\mathrm{EaD}$; e $15,66 \%$ responderam que na $\mathrm{EaD}$ o aluno aprende melhor do que na educação presencial. Abaixo, destacam-se três falas dos tutores virtuais (Comentários 5, 6 e 7) que ilustram os motivos pelos quais a maior parte dos pesquisados considera que a aprendizagem se dá igualmente nas modalidades presencial e EaD.

O que define a aprendizagem não é a modalidade de ensino, mas sim a qualidade das propostas, a disposição ao aprendizado, entre outras. (Comentário 5 - Docente Virtual E).

Se há o mesmo comprometimento e envolvimento de todos, a aprendizagem é a mesma, o que muda é, apenas, a modalidade (presencial, semipresencial, a distância). (Comentário 6 - Docente Virtual F).

$\mathrm{Na}$ verdade, o aprendizado independe do meio (presencial ou virtual). Escolhi a resposta da igualdade, porque entendo que as condições são iguais. (Comentário 7 - Docente Virtual G).
A constatação de que para a maior parcela dos tutores o aprendizado se faz igualmente em ambas as modalidades contribui para se pensar que a prática pedagógica na $\mathrm{EaD}$ pode favorecer a formação do conhecimento pedagógico do conteúdo. De acordo com Migliorança (2010,p. 48), esse conhecimento é aprendido com o exercício da profissão docente e aprimorado no processo de reflexão sobre essa prática. Dessa maneira, o conhecimento pedagógico do conteúdo oportuniza ao professor contextualizar o ensino, voltando-o às necessidades discentes. De forma complementar, Mesa (2001) destaca que, por esse conhecimento, o conteúdo é transformado para ser ensinado, e, assim, é por ele que se distingue o docente do profissional que possui apenas a formação de especialista em determinada área.

\section{Os saberes formados na prática profissional}

Os saberes que constituem a base de conhecimento para o exercício da profissão docente possuem várias fontes de formação, conforme explicitado nas seções anteriores. O Quadro 1 sintetiza esse processo.

Quadro 1 - Base de conhecimento da docência e as fontes para sua constituição

\begin{tabular}{|l|l|l|l|}
\cline { 2 - 4 } \multicolumn{1}{c|}{} & \multicolumn{3}{|c|}{ Base de conhecimento da docência } \\
\hline É formada por & $\begin{array}{l}\text { Conhecimento do } \\
\text { conteúdo específico } \\
\text { (saberes disciplinares) }\end{array}$ & $\begin{array}{l}\text { Conhecimento } \\
\text { pedagógico em geral } \\
\text { (saberes profissionais; } \\
\text { saberes pedagógicos; } \\
\text { saberes curriculares) }\end{array}$ & $\begin{array}{l}\text { Conhecimento } \\
\text { pedagógico do } \\
\text { conteúdo }\end{array}$ \\
\hline $\begin{array}{l}\text { Fontes para sua } \\
\text { constituição } \\
\text { experienciais })\end{array}$ \\
\hline $\begin{array}{l}\text { Quando se } \\
\text { constitui }\end{array}$ & Formação acadêmica & $\begin{array}{l}\text { Pesquisa sobre educação; } \\
\text { Materiais e contexto } \\
\text { do processo educativo } \\
\text { institucionalizado }\end{array}$ & $\begin{array}{l}\text { Sabedoria da } \\
\text { prática ou prática } \\
\text { profissional da } \\
\text { docência }\end{array}$ \\
\hline
\end{tabular}

Fonte: Elaborado pelos autores deste artigo, com base nos textos de Shulman (1986, 2005), Tardif (2012) e Mizukami (2004).

4 No caso dos cursos de licenciatura, os saberes pedagógicos podem ser construídos durante a formação inicial. 
Observando-se o Quadro 1, nota-se que a base de conhecimento da docência começa a ser constituída durante a formação inicial, período em que as vivências como aluno, os referenciais e as impressões sobre as atitudes dos professores que se teve ao longo da trajetória como estudante também influenciam. Com o passar dos anos, contudo, a experiência proveniente da prática pedagógica profissional pode aprofundar, ampliar e diversificar essa base (MIZUKAMI, 2004).

Esse mesmo argumento é reforçado por Tardif (2012), para quem a prática profissional é uma fonte para a formação docente, pois, por meio dela, os professores retraduzem sua formação inicial, ampliando sua base de conhecimento. Em outras palavras, por meio da prática pedagógica cotidiana, os professores têm a oportunidade de rever, julgar e avaliar os saberes da formação inicial (TARDIF, 2012).

Na pesquisa, identificou-se falas (Comentários 8 e 9) a respeito da formação pela experiência.

Em minha atividade profissional, pude adquirir experiência em uma atividade que me era desconhecida, para poder transmitir a meus alunos presenciais que são futuros (e alguns já atuais) professores. (Comentário 8 - Docente Virtual H).

Todas as minhas experiências docentes foram significativas, porque me deram experiência e desenvoltura para trabalhar com todas as idades e níveis de formação. (Comentário 9 - Docente Virtual I).

Pelos Comentários desses docentes, é possível verificar que os tutores virtuais pesquisados formam-se na prática profissional, aproveitando suas experiências nos diferentes níveis e modalidades de ensino para aprimorar-se e ampliar sua base de conhecimento da docência.

\section{0 tutor virtual e os saberes que constrói na mediação pedagógica em AVA}

Por ser parte da polidocência, o tutor virtual necessita de saberes da base de conhecimentos da docência em geral e, como afirma Mill (2014), a atuação como mediador do ensino-aprendizagem no ambiente virtual de aprendizagem exige outros conhecimentos que são específicos à EaD. Além disso, as atribuições do tutor virtual (bem como seus saberes docentes) podem variar conforme a proposta do curso ou o modelo de EaD adotado pela instituição em que atua (MILL, 2014). De forma geral, seu papel agrega atividades relativas ao atendimento aos alunos e à mediação pedagógica nos AVA e, para tanto, necessita de saberes como:

a) conhecer a proposta curricular, bem como os materiais didáticos do curso para que possa estimular os estudantes e orientá-los nos exercícios;

b) dominar a disciplina que tutoria;

c) ter ciência das especificidades do seu trabalho no AVA e de sua rotina;

d) conhecer o perfil do aluno cursista;

e) ter habilidades na comunicação e linguagem escrita para esclarecer as dúvidas quanto ao conteúdo estudado;

f) dominar os recursos tecnológicos por meio dos quais atua para que possa auxiliar os alunos quanto a questões técnicas;

g) conhecer diferentes estratégias pedagógicas e didáticas para utilizá-las na motivação dos alunos;

h) dominar o AVA para que possa gerenciá-lo de forma satisfatória;

i) saber comunicar-se para dar feedbacks formativos na correção das atividades;

j) ter habilidades socializadoras para promover as interações entre os alunos e ele e entre os próprios alunos de forma a motivar a aprendizagem colaborativa;

k) saber trabalhar de forma coletiva para interagir com os demais profissionais da polidocência.

Contudo, a maior parte dos saberes supramencionados não faz parte da formação inicial dos tutores virtuais. Assim, baseando-se em Tardif (2012), é possível dizer que são construídos na mediação pedagógica nos AVA, constituindo-se em saberes experienciais. Além disso, dados obtidos durante a investigação mostraram que uma parte dos saberes específicos à tutoria virtual é formada pela interação com profissionais que possuem mais tempo de experiência na função.

Superei [as dificuldades iniciais na tutoria virtual] com muita insistência, aqui no campus trocamos ideias entre os que fazem tutoria (Comentário 10 Docente Virtual J). 
Sobre os conhecimentos e saberes construídos a partir da experiência como tutor virtual, obteve- -se as informações categorizadas e organizadas no Quadro 2.5

Quadro 2 - Conhecimentos e saberes formados a partir da prática pedagógica na EaD

\begin{tabular}{|l|c|c|}
\hline \multicolumn{1}{|c|}{ Categorias } & \multicolumn{2}{c|}{$\begin{array}{l}\text { Respostas que se enquadram na } \\
\text { categoria }\end{array}$} \\
\cline { 2 - 3 } & Porcentagem & Quantidade \\
\hline $\begin{array}{l}\text { Conhecimentos e saberes relativos às tecnologias digitais e ao } \\
\text { ambiente virtual de aprendizagem }\end{array}$ & $39,02 \%$ & 32 \\
\hline $\begin{array}{l}\text { Conhecimentos e saberes relativos à modalidade de educação a } \\
\text { distância }\end{array}$ & $25,60 \%$ & 21 \\
\hline $\begin{array}{l}\text { Conhecimentos e saberes relativos à linguagem e à comunicação } \\
\text { escrita }\end{array}$ & $24,39 \%$ & 20 \\
\hline $\begin{array}{l}\text { Conhecimentos e saberes relativos à relação ensino-aprendizagem } \\
\text { nos AVA }\end{array}$ & $19,51 \%$ & 16 \\
\hline Conhecimentos e saberes relativos ao perfil dos alunos & $14,63 \%$ & 12 \\
\hline Conhecimentos e saberes relativos aos conteúdos disciplinares & $12,19 \%$ & 10 \\
\hline Conhecimentos e saberes relativos à organização do tempo & $7,31 \%$ & 6 \\
\hline $\begin{array}{l}\text { Conhecimentos e saberes relativos ao trabalho colaborativo e } \\
\text { cooperativo }\end{array}$ & $6,09 \%$ & 5 \\
\hline Conhecimentos e saberes relativos à atuação do tutor virtual & $4,87 \%$ & 4 \\
\hline Conhecimentos e saberes didático-pedagógicos & $4,87 \%$ & 4 \\
\hline
\end{tabular}

Fonte: Elaborado pelos autores deste artigo.

Analisando o Quadro 2, é possível observar alguns aspectos. Primeiro, uma porcentagem maior de construção de saberes relacionados às tecnologias digitais e ao ambiente virtual de aprendizagem. Segundo Moore e Kearsley (2008, p. 147), os tutores virtuais "precisam descobrir sozinhos as limitações e o potencial da tecnologia e as melhores técnicas para comunicação por meio dessa tecnologia". Essa constatação leva à compreensão de que os tutores aprendem sobre as tecnologias atuando na prática, enquanto mediadores do processo de ensino-aprendizagem nos AVA.

Em segundo lugar, verifica-se a construção de conhecimentos relacionados à modalidade EaD. Quanto a isso, apoiando-se em Ribeiro, Mill e Oliveira (2010), compreende-se que a tutoria virtual pode ser vista como uma oportunidade de desenvolvimento profissional, uma vez que, a partir dela, os tutores constroem novos saberes que serão incorporados à base de conhecimento necessária à docência, ampliando-a.
Em relação ao conhecimento relacionado à linguagem e à comunicação escrita, que aparece em terceiro lugar no Quadro 2, Mill et al. (2008) esclarecem que são saberes específicos da tutoria, no sentido em que o tutor virtual torna-se mais atento ao que lê e escreve no AVA, pois disso depende seu papel de mediador do processo de ensino-aprendizagem. Também Peters (2009) ressalta que esses saberes são imprescindíveis no atual cenário educacional, uma vez que a acelerada expansão da modalidade EaD mediada pelas TDIC exige, cada vez mais, formas de comunicação compactadas e globalizadas.

As respostas relativas aos conhecimentos e saberes sobre a relação ensino-aprendizagem nos AVA e sobre o perfil dos alunos indicam que a interação entre os alunos e os tutores virtuais está sendo favorecida no modelo de EaD adotado pela

\footnotetext{
5 O Quadro 2 foi organizado a partir de uma pergunta aberta do questionário enviado aos tutores virtuais. Dos 83 que completaram o preenchimento do questionário, 82 responderam a essa questão.
} 
Rede e-Tec Brasil/IFSP. Isso, segundo Moore e Kearsley (2008), é essencial e altamente desejável, tanto para os tutores quanto para os alunos, em cursos dessa modalidade. Ainda quanto a essa categoria de saberes e conhecimentos, baseando-se em Ribeiro, Mill e Oliveira (2010, p. 53), é possível dizer que "os docentes consideram o contato direto com os alunos como uma fonte importante de informações para o bom andamento da disciplina". Disso decorre que a ausência de interação seria um elemento dificultador da prática pedagógica na modalidade.

Acerca dos conhecimentos e saberes relacionados aos conteúdos disciplinares, como já foi dito anteriormente, percebe-se que os participantes da pesquisa os valorizam como fundamentais para as interações que se estabelecem no AVA.

Por fim, a indicação de saberes e conhecimentos acerca da organização do tempo, do trabalho colaborativo e cooperativo, da atuação do tutor virtual e dos didático-pedagógicos demonstra que a tutoria virtual pode contribuir para o aprimoramento da docência, ampliando a base de conhecimento desses profissionais.

\section{Considerações finais}

Este artigo teve como objetivo mapear os saberes do tutor virtual, identificando sua natureza.
Participaram da investigação tutores virtuais que atuam nos cursos técnicos oferecidos a distância pelo IFSP, por meio da Rede e-Tec Brasil. Os estudos de Shulman $(1986,2005)$, bem como a categorização proposta por Mizukami (2004), trouxeram o referencial teórico para as análises sobre a base de conhecimento necessária ao exercício da docência. A análise sobre os saberes docentes, especialmente os saberes experienciais, embasaram-se em Tardif (2010, 2012).

Os resultados obtidos com a investigação demonstraram, em primeiro lugar, que os tutores virtuais valorizam o conhecimento do conteúdo específico para sua atuação como mediadores nos AVA. Em segundo lugar, que a prática na tutoria virtual potencializa a ampliação dos saberes relativos ao conhecimento pedagógico em geral. Em terceiro lugar, observou-se que a atuação como tutor virtual potencializa a formação do conhecimento pedagógico do conteúdo, especialmente no que se refere a considerar o perfil do aluno e suas dificuldades para escolher as melhores e mais apropriadas estratégias de ensino-aprendizagem.

Sendo assim, a investigação empreendida possibilita pensar, a partir dos conhecimentos específicos à tutoria virtual, que essa experiência tem potencial formador, uma vez que oportuniza a construção de novos saberes e a ampliação da base de conhecimento necessária à profissão docente.

\section{REFERÊNCIAS}

COORDENAÇÃO DE APERFEIÇOAMENTO DE PESSOAL DE NÍVEL SUPERIOR (CAPES). Sobre as áreas de avaliação. Brasília, 2014. Disponível em: <http://www.capes.gov.br/avaliacao/sobre-as-areas-de-avaliacao>. Acesso em: 16 jun. 2013.

DUARTE, T. A possibilidade de investigação a três: reflexões sobre a triangulação (metodológica). CIES e-WorkingPaper, Lisboa, n. 60, p. 1-24, 2009.

MESA, L. M. La construcción del conocimiento en la enseñanza. In: GARCÍA, C. M. et al. (Org.). La función docente. Madrid: Editorial Síntesis, 2001. p. 47-83.

MIGLIORANÇA, F. Programa de Mentoria da UFSCar e desenvolvimento profissional de três professoras iniciantes. 2010. 347 f. Tese (Doutorado em Educação) - Universidade Federal de São Carlos, São Carlos, 2010.

MILL, D. Sobre o conceito de polidocência ou sobre a natureza do processo de trabalho pedagógico na Educação a Distância. In: MILL, D.; OLIVEIRA, M. R. G.; RIBEIRO, L. R. C. (Org.). Polidocência na educação a distância: múltiplos enfoques. 2. ed. São Carlos: EdUFSCar, 2014. p. 23-40.

MILL, D. et al. O desafio de uma interação de qualidade na Educação a Distância: o tutor e sua importância nesse processo. Cadernos da Pedagogia, São Carlos, ano 2, v. 2, n. 4, p. 112-127, ago./dez. 2008.

MIZUKAMI, M. G. N. Aprendizagem da docência: algumas contribuições de L. S. Shulman. Revista do Centro 
de Educação, Santa Maria, v. 29, n. 2, p. 1-11, 2004. Disponível em: <http://coralx.ufsm.br/revce/revce/2004/02/ a3.htm>. Acesso em: 09 mar. 2012.

MOORE, M. G; KEARSLEY, G. Educação a Distância: uma visão integrada. São Paulo: Cengage Learning, 2008 PETERS, O. A Educação a Distância em transição: tendências e desafios. São Leopoldo: Editora da Unisinos, 2009.

REALI, A. M. de M. R.; TANCREDI, R. M. S. P.; MIZUKAMI, M. G. N. Programa de mentoria online: espaço para o desenvolvimento profissional de professores iniciantes e experientes. Educação e Pesquisa, São Paulo, v. 34, n. 1, p. 77-95, jan./abr. 2008.

RIBEIRO, L. R. C.; MILL, D.; OLIVEIRA; M. R. G. A docência virtual versus presencial sob a ótica dos professores. In: MILL, D.; OLIVEIRA, M. R. G.; RIBEIRO, L. R. C. (Org.). Polidocência na educação a distância: múltiplos enfoques. São Carlos: EdUFSCar, 2010. p. 41-58.

SHULMAN, L. S. Conocimiento y enseñanza: fundamentos de la nueva reforma. Profesorado: Revista de currículum y formación del profesorado, Granada, v. 9, n. 2, p. 1-28, 2005. Disponível em: <http://www.ugr.es/local/ recfpro/Rev92ART1.pdf $>$. Acesso em: 15 maio 2012.

. Those who understand: knowledge growth in teaching. Educational Researcher, v. 15, n. 2, p. 4-14, 1986. Disponível em: <http://www.fisica.uniud.it/URDF/masterDidSciUD/materiali/pdf/Shulman_1986.pdf>. Acesso em: 15 maio 2013.

TARDIF, M. Saberes docentes e formação profissional. 13. ed. Petrópolis: Vozes, 2012.

Os saberes dos professores. In: OLIVEIRA, D. A.; DUARTE, A. M. C.; VIEIRA, L. M. F. Dicionário:

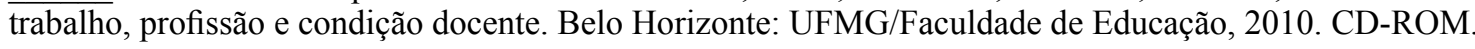

Recebido em: 01.05.2015

Aprovado em: 10.09 .2015 